\title{
Novel technique for endoscopic retrieval of a ring-shaped gastric foreign body
}

\author{
B Nondela, ${ }^{1}$ M Arnold, ${ }^{2} \mathrm{~S} \mathrm{Cox}^{3}$ \\ ${ }^{1}$ Registrar, Division of Paediatric Surgery, Red Cross War Memorial Children's Hospital, University of Cape Town, South \\ Africa \\ ${ }^{2}$ Paediatric Surgery Consultant, Division of Paediatric Surgery, Red Cross War Memorial Children's Hospital, University of \\ Cape Town, South Africa \\ ${ }^{3}$ Head of Clinical Unit, Division of Paediatric Surgery, Red Cross War Memorial Children's Hospital, University of Cape \\ Town, South Africa
}

Corresponding author: Babalwa Nondela (bbnondela@gmail.com)

\author{
Summary: We present a novel technique for retrieval of a retained ring-shaped gastric FB that is accessible, safe, reliable \\ and cost-effective. \\ Keywords: Gastric foreign body, ring, endoscopy

\section{Case report:}

A previously well, asymptomatic 2-year-old boy presented 8 hours after having ingested his mother's wedding ring. Plain abdominal radiograph located the ring in the stomach (Figure 1a). The anxious mother was reassured that the ring would pass per rectum, and was instructed to monitor the stools for the next few days. She was advised to return if the child developed symptoms of gastric outlet obstruction, or if the ring had not been passed within 4 weeks. He returned 4 weeks later, still asymptomatic. The ring was located in the stomach on Lodox $^{\circledR}$ (low dose $\mathrm{x}$-ray) imaging (Figure 1b). Flexible upper GI endoscopy under general anaesthesia revealed the ring in the gastric cardia. The ring was manoeuvred to a suitable position in the antrum for retrieval by positioning the patient on his right side. Multiple attempts at retrieval using multiple instruments including a range of biopsy forceps and a retrieval basket were unsuccessful, the jaws of the biopsy forceps and the basket being too small.

Thereafter, a novel approach using an orogastric tube (OGT) passed alongside the flexible endoscope (Figure 2). An $8 \mathrm{~F}$ orogastric tube was passed into the stomach. The endoscope was re-introduced followed by the biopsy forceps via the instrument channel of the scope. The OGT was guided through the centre of the ring. The tip of the OGT was then grasped using the biopsy forceps. The endoscope, forceps, ring and OGT were removed as a unit with no significant trauma. The patient was commenced on full feeds immediately postoperatively and discharged the same day.

\section{Discussion}

Foreign body (FB) ingestion in children is a common problem in the early exploratory phase of childhood, with a peak incidence at 3 years of age. ${ }^{1,2}$ Commonly ingested foreign bodies that get lodged are coins, batteries and small toys. ${ }^{2}$ Wedding rings are uncommon. Most ingested objects pass through the GIT without serious sequelae. Foreign bodies get lodged in any of the three narrow points in the oesophagus: the cricopharyngeal area, the middle third of the oesophagus where the aortic arch and left main bronchus cross the oesophagus or the lower oesophageal sphincter.,

Abdominal symptoms are often nonspecific and do not help in anatomically locating the FB. ${ }^{5}$ Biplanar plain radiographs act as a guide to the location of the foreign body. We make use of Lodox ${ }^{\circledR}$ as a valuable screening method to take a single image in each plane to visualise the entire GIT with minimal radiation exposure. For the $20 \%$ of FBs that require removal, ${ }^{1,3}$ rigid or flexible oesophagoscopy under general anaesthesia is usually recommended, and only about $1 \%$ will need open or laparoscopic surgery. ${ }^{1}$

Removal of blunt foreign bodies and coins or impacted food from the oesophagus should be done urgently ( $<24$ hours), even in asymptomatic children. If the child is symptomatic an emergent $\left(<2\right.$ hours) removal is indicated. ${ }^{6}$

Once through the oesophagus, the majority of FBs pass through the GIT uneventfully, with other possible hold-up points being the pylorus and ileocaecal valve. Endoscopic removal of blunt foreign bodies from the stomach or duodenum is also recommended if the child is symptomatic or if the object is wider than $2.5 \mathrm{~cm}$ in diameter or longer than 


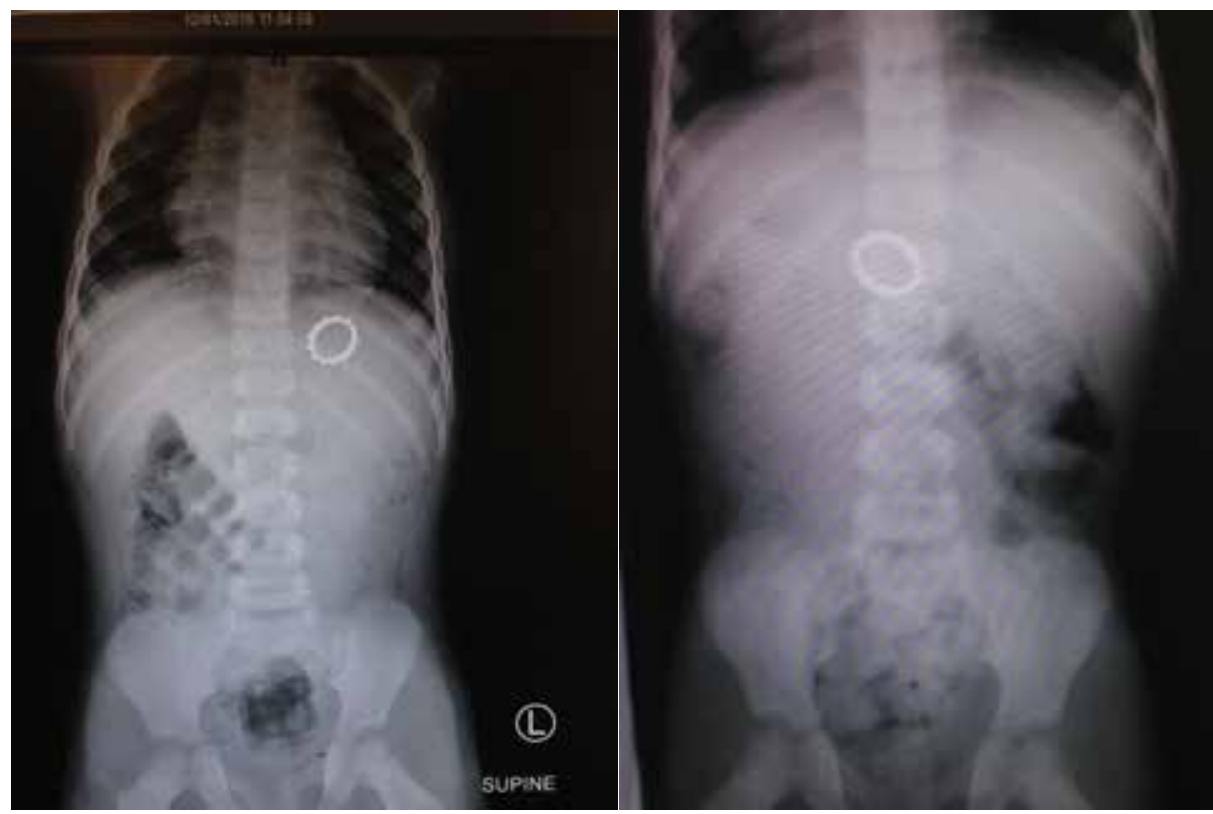

Figure 1: a) Initial plain abdominal x-ray showing ring in stomach, (b)Lodox, AP view 4 weeks later showing ring in the stomach.

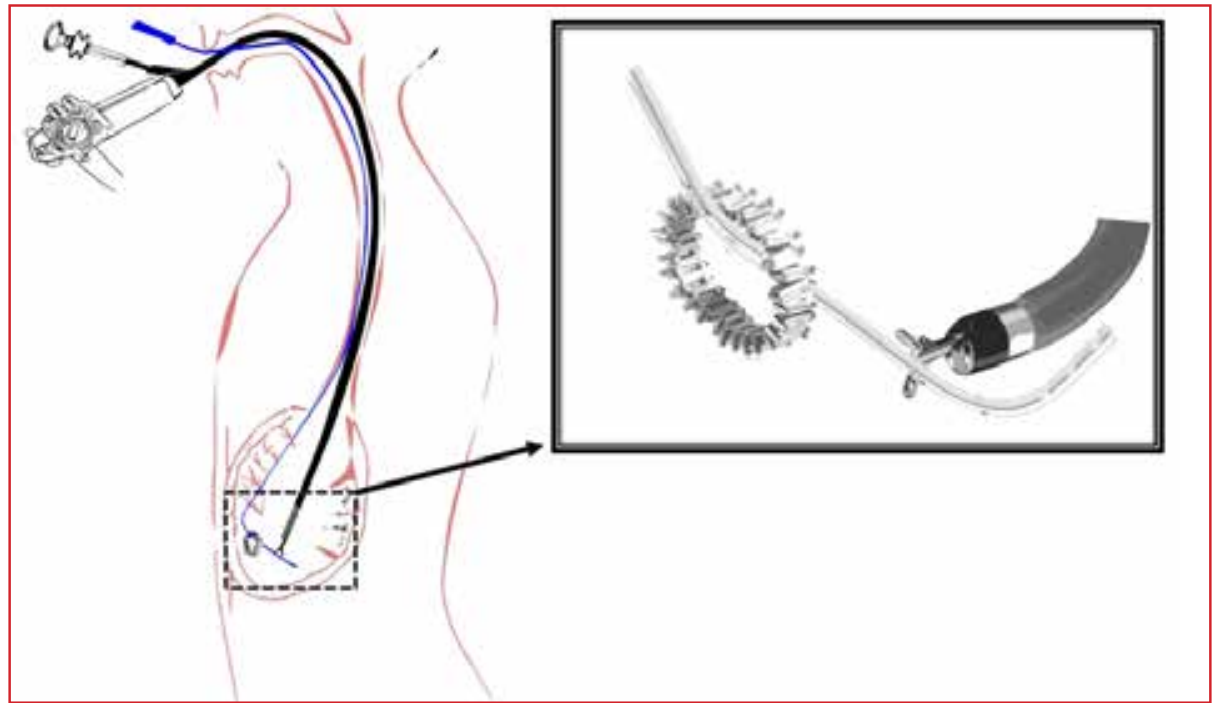

Figure 2: Diagram demonstrating the oro-gastric tube(OGT) passed alongside the endoscope into the stomach. The OGT passed through the ring and grasped at the tip by biopsy forceps passed through the endoscope instrument channel. The scopeforceps-ring and OGT were pulled out of the mouth as a unit. [Diagram courtesy of Dr S. Emre, Department of Pediatric Surgery, Istanbul University]

$6 \mathrm{~cm}$ in length. Other blunt FBs in the stomach can be managed expectantly and retrieved only if they produce symptoms. ${ }^{2}$ A foreign body that has not managed to progress beyond the stomach after 4 weeks is unlikely to pass spontaneously, and should be removed due to the risk of gastric outlet obstruction, ${ }^{1}$ as it was the concern in our case.

Retained gastric FBs are challenging to remove even for experienced endoscopists with an abundant array of retrieval instruments, as it was in our case. Equipment that should ideally be readily available for the procedure includes: rat tooth and alligator forceps, polypectomy snare, polyp grasper, Dormia basket and retrieval net. Many institutions do not have the whole range of retrieval equipment but most do have a feeding orogastric tube and simple biopsy forceps, such as we used in our case successfully and with ease.

\section{Conclusion}

We propose use of this safe, reliable and relatively inexpensive novel technique in challenging retrieval of gastric FBs with a lumen.

\section{REFERENCES}

1. Kay M, Wyllie R. Pediatric foreign bodies and their management. Current gastroenterology reports. 1 May 2005;7(3):212-8.

2. Hesham A, Kader H. Foreign body ingestion: children like to put objects in their mouth. World J Pediatr. 1 Nov 2010;6(4):301-10.

3. Burgos A, Rábago L, Triana P. Western view of the management of gastroesophageal foreign bodies. World J Gastrointest Endosc. 10 May 2016;8(9):378.

4. Lee JH, Lee JH, Shim JO, Lee JH, Eun BL, Yoo KH. Foreign body ingestion in children: Should button batteries in the stomach be urgently removed? Pediatr Gastroenterol Hepatol Nutr. 2016;19(1):20-28. doi:10.5223/pghn.2016.19.1.20

5. Eisen GM, Baron TH, Dominitz JA, Faigel DO, Goldstein JL, Johanson JF, Mallery JS, Raddawi HM, Vargo JJ, Waring JP, Fanelli RD. Guideline for the management of ingested foreign bodies. Gastrointest Endosc. 30 Jun 2002;55(7):802-6.

6. Tringali A, Thomson M, Dumonceau JM, Tavares M, Tabbers MM, Furlano R, et al. Pediatric gastrointestinal endoscopy: European Society of Gastrointestinal Endoscopy (ESGE) and European Society for Paediatric Gastroenterology Hepatology and Nutrition (ESPGHAN) Guideline Executive summary. Endoscopy. Jan 2017;49(01):83-91. 